\title{
THE EFFECTS OF DIGITAL PROMOTION INVESTMENT IN CROATIA'S TOURISM PRODUCT
}

\author{
Davorin Turkalj \\ Antun Biloš \\ Renata Deželjin
}

https://doi.org/10.20867/tosee.05.3

\begin{abstract}
The growing interest of foreign tourists in Croatia's tourism offerings could be attributed to the Croatian National Tourist Board (CNTB) increased promotional efforts, with special emphasis on digital ones. Based on the data provided, the authors' aim is to determine the state and potential of utilizing online channels to enhance their effectiveness in online promotion. The data analyzed in this paper enable the authors to suggest trends concerning the choice of digital platforms for communication and intensity of further investments. Quantitative secondary data used and analyzed in this paper are collected from the official CNTB website and also official annual reports. The paper focuses on the period between 2014 and 2016, due to the introduction of Croatian Strategic Tourist Marketing Plan 2014-2020 in 2014. The authors examine digital promotion investments of the CNTB as well as the choice of individual digital communication channels. The data presented in this paper enable authors to conclude if certain online promotion investments were justified and to establish the number of visits that happened consequently. By analyzing these data, it is possible to predict and advise a further increase in the latest forms of digital promotion which would lead to better customer understanding of Croatia's diverse tourism offerings. Authors also recognize the rising importance of mobile presence when it comes to the promotion of tourism products, services, and destinations.
\end{abstract}

Keywords digital, promotion, tourism, Croatia, investment

\section{INTRODUCTION}

In recent years, there has been a noticeable trend in online customer behaviour visible through several distinct behaviour patterns. Users spend more time online, they consult online resources at significant levels and seek information for various goals; their behaviour is highly driven by their intent (Adams et al., 2015) and related context. The significance of context is becoming popular in travel and tourism industry in areas such as location-based services (Lamsfus et al., 2013) enabled by omnipresent mobile devices and application which rely heavily on the concept. The related term 'micro-moment' as an approach of describing an apparent trend, started to appear more frequently in internet information space around 2012 but was made popular by Google-related authors, among others, during 2015 (Biloš et al., 2016).

Ramaswamy (2015) describes micro-moments as moments of "decision-making and preference-shaping" that occur during the entire user journey and ultimately determine the end result of that user experience. Micro-moments occur when users reach for a digital device to act on any sort of need with immediate effect. In these moments, user expectations are high because modern, digitally savvy users expect companies to 
ToSEE - Tourism in Southern and Eastern Europe, Vol. 5, pp. 715-728, 2019

D. Turkalj, A. Biloš, R. Deželjin: THE EFFECTS OF DIGITAL PROMOTION INVESTMENT IN ...

anticipate their needs (Husson \& Ask, 2014). Adams et al. (2015) suggest 4 major categories of micro-moments: I-want-to-know, I-want-to-go, I-want-to-buy, and I-wantto-do moments. However, additional categories or sub-categories of micro-moments are also mentioned or explored in several articles. So-called micro-moments in tourism, can be described as moments that people interested in travel arrangements are experiencing as a form of a customer journey in the online environment. These moments consist of browsing, researching, making the decision and finalizing the purchase via the Internet. Keeping up with the mentioned trend greatly influences and also justifies increased investment in online campaigns aimed at promoting tourism products and services. The main objective of this paper is to analyze online tourist behaviors by monitoring the chosen channels of communication and parameters that are driving those behaviors, represent the main motivation in exploring this subject.

\section{THEORETICAL BACKGROUND AND LITERATURE REVIEW}

The global digitalisation has undoubtfully had a significant impact on tourism both for providers and consumers alike (Standing et al., 2014). Internet as a primary medium of digitally connected world has been utilized for communication activities of tourist destinations for quite some time. It enabled promotion of destination management organizations (DMOs) and tourism operators, such as hotels, tour and travel agents, restaurants and tourism industry networks while sharing information related to tourism product. This topic was intriguing for many researchers from often different viewpoints (Sambhanthan \& Good, 2016; Hernández-Méndez \& Muñoz-Leiva, 2015; Fatanti \& Suyadnya, 2015; Stienmetz et al., 2015; Buhalis \& Wagner, 2013; Hays et al., 2012; Saß, 2011) especially when acknowledging the fact that tourism has become an substantial part of the GDP in many countries around the world (Míguez-González \& FernándezCavia, 2015).

Kronenberg et al. (2015) conducted a research focused on the effect of advertising on international tourism demand at the destination level and showed that advertising is a significant factor of tourism demand while income and tourism price levels were found less significant. Internet based technology together with a realistic use of the online communication channel are already proven marketing tools and even often described as key success factor of DMO communication (Inversini et al., 2011). Furthermore, online promotion can improve the destination loyalty (Lai \& Vinh, 2013) but can equally have both positive and negative implications on potential tourists (Yazdanifard \& Yee, 2014; $\mathrm{Sa}, 2011)$.

Several authors emphasized the role of social media in DMOs communication efforts. Social media is described as an essential tool in the hospitality and tourism industry (Yazdanifard \& Yee, 2014). Morosan (2015) observes an "unprecedented increase" in the popularity of social media involvement in tourism marketing. Furthermore, the presence of social media channels plays an important role in establishing a tourism destination as a brand in general terms (Fatanti \& Suyadnya, 2015). However, Hays et al. (2012) suggested that social media usage among tourist organizations is still somewhat experimental and that applied strategies vary significantly, based on a study conducted in UK. Online customer orientation was and is of utmost significance for the 
ToSEE - Tourism in Southern and Eastern Europe, Vol. 5, pp. 715-728, 2019

D. Turkalj, A. Biloš, R. Deželjin: THE EFFECTS OF DIGITAL PROMOTION INVESTMENT IN ...

entire marketing process. Christou (2011) proposed that tourism related marketing activities should consider the importance of online customer awareness and personal attributes as well as an adequate segmentation.

Based on observed scientific literature and research efforts, it can be concluded once again (Hernández-Méndez \& Muñoz-Leiva, 2015) that the literature review did not produce conclusive results suggesting that the findings could be highly determined by the context of the research and other factors. Finally, it can be generally observed that different advertising channels are in fact complementary (Morosan, 2015) and that they work together to produce the desired communication goals.

\section{ANALYSIS OF DIGITAL PROMOTION ACTIVITIES OF CROATIAN NATIONAL TOURIST BOARD (CNTB)}

The Croatian National Tourist Board (CNTB) is the national tourism organization founded with a goal to promoting Croatia as a tourism destination both at home and abroad. The main sources of information for tourists visiting Croatia are their prior travel experiences to the country (35\%), followed by the Internet (30\%), a recommendation by relatives and friends (27\%), and other media (20\%) (Institut za turizam, 2015). The 2013 data on the EU averages show that $56 \%$ of tourists relied on recommendations for information about a destination, $40 \%$ relied on the Internet, while $4 \%$ used other sources. When using the Internet as a source of information, $51 \%$ of tourists visit accommodation websites, 39\% use social networks (Facebook, Instagram, Twitter), 37\% visit the websites of Croatian tourist board offices, while $34 \%$ use online travel agencies. $40 \%$ of tourists post their holiday photos on social networks, $27 \%$ update their status with details from their trip, $5 \%$ update their location, $4 \%$ post video content, while $3 \%$ write reviews on online platforms such as TripAdvisor (Institut za turizam, 2015).

The 2014 National Tourist Brand Tracking survey (Ipsos, 2015) conducted by the CNTB explored the perceptions, opinions and associations that inbound tourists have of Croatia as a tourism destination, and identified their travel habits. In particular, the survey focused on their use of social media while planning for and during the vacation. The survey results show that approximately $86 \%$ of tourists use social media; the rest do not. The most popular social networks are Facebook (72\%), YouTube $(43 \%)$, Google+ (23\%), Twitter (19\%), Instagram (17\%) and Pinterest (9\% \%). Social networks are mainly used for planning a trip, as well as for choosing a destination and attractions to visit during the trip. Tourists look for content which provides interesting and useful information about the destination, as well as traveller reviews. The CNTB's Facebook page for Poland has the largest number of fans (27\%), while the one for the Netherlands has the lowest number of fans (about 2\%). The CNTB Facebook pages are popular among Polish and Italian tourists under the age of 40; those with below-average income and past guests. Twitter is also preferred by Poles and Italians, past guests, and men rather than women. Instagram is favoured by tourists from Germany and Poland, and those under the age of 30 . 
ToSEE - Tourism in Southern and Eastern Europe, Vol. 5, pp. 715-728, 2019

D. Turkalj, A. Biloš, R. Deželjin: THE EFFECTS OF DIGITAL PROMOTION INVESTMENT IN

Croatia is a popular inbound tourism market, as evidenced by, among other things, intensive exchange of experiences, opinions and information by social media users. They mainly discuss their own travel experiences in Croatia, give each other advice, and ask each other questions about their trip. Forums and social networks are the preferred platforms for conversation and interaction about Croatia in all the surveyed markets. Twitter is very popular in Great Britain, while it does not enjoy popularity among the Poles. Italians mainly use blogs and Facebook. The forums are used mostly when searching for information about accommodation or restaurants, when planning an itinerary, etc. Blogs are a great medium when one is looking for detailed travel descriptions, photos and videos, while Twitter and Facebook are used for shorter messages/comments, e.g. enthusiastic messages about one's upcoming trip. Websites with general reviews are quite popular in Great Britain and Poland (HTZ, 2013).

In the course of one year, the CNTB typically conducts four major campaigns, two preand postseason campaigns, and two brand campaigns. The former is aimed at increasing the off-season demand, and the latter at raising brand awareness and at brand building.

The CNTB has an official website. In addition, a separate webpage is created whenever a new brand campaign is launched. Since 2009, it promotes Croatia on major websites, search engines, and social networks. It also uses email newsletters, mobile marketing, and business pages. The goals of the CNTB's online promotion are Croatian tourism brand positioning, raising awareness of and increasing the off-season demand; increasing the average spending of tourists; reaching a global audience; increasing engagement, content sharing, and connectivity with visitors.

Considering current market conditions, trends, and the importance of advertising and online media in tourism, in general, online advertising has become the most important part of the CNTB's marketing activities. It has been doing it since 2009 using Google Ads, the world's largest advertising network that displays ads on the Google Search Network and the Google Display Network (various partnership, interest, information, and thematic tourism product websites) (Lawson, 2018). Until 2015, the CNTB had advertised mostly using keywords and visual banner ads on websites and social networks. In 2015, approach to online advertising was changed to targeting key users. Also, the focus was shifted towards large interactive adverts, advertorials and latest interactive tools (video ads, mobile banners, sponsorship button, pre-roll video, infographics, etc.), use of native advertising for a better/more natural user experience, etc. This proved to be successful because of the greater interactivity of promotional materials. In addition, users of different age groups/purchasing power/interests are now targeted by using advanced segmentation methods and well-known online services and applications (Skype, online music streaming apps like Spotify, and others). In 2016, native advertising and story telling took centre stage. To exploit the potential of these two advertising categories, a campaign was launched titled Croatia Feeds and a website created with the same name, which tells stories about Croatia in a modern, intriguing way. 
ToSEE - Tourism in Southern and Eastern Europe, Vol. 5, pp. 715-728, 2019

D. Turkalj, A. Biloš, R. Deželjin: THE EFFECTS OF DIGITAL PROMOTION INVESTMENT IN ...

\subsection{Online portal advertising}

Online advertising on major portals is done on Croatia's largest inbound markets, i.e. Austria, Belgium, the Czech Republic, France, Italy, the Netherlands, Germany, Poland, Norway, Sweden, Denmark, Finland, Slovakia, Slovenia, Spain, Switzerland, and Great Britain. The United States and Japan used to be in this group as well. In cooperation with its representative offices, the CNTB develops a media plan for online portal advertising on Croatia's inbound markets in accordance with the Strategic Marketing Plan for Croatian Tourism (SMPCT). Ads are produced for selected products and various geo zones in different languages.

Table 1 shows that display advertising is becoming more and more important since the advertising budget increased compared to previous years: in 2014 , it increased by $74 \%$, in 2015 by $56 \%$, while in 2016 it decreased by $31 \%$ compared to 2015 .

\subsection{Search engine advertising}

Search engine advertising is a method of advertising on the most popular search engines using keywords that are relevant to users. The advertiser's presence during the target consumer's search is important for creating visibility and recognition as well as for providing useful information. For advertising on Google, monthly budgets and market plans have been drawn up for individual markets based on search statistics on users' searches of terms related to Croatian tourism or tourism in general, with a focus on key markets and their preferences. This was then used to launch campaigns with creative ads and keywords for individual markets. An Advertising Agreement with Google Ltd. was signed in 2014 for the following markets: Austria, Belgium, the Czech Republic, France, Italy, Japan, Hungary, the Netherlands, Germany, Poland, Russia, the US, Norway, Sweden, Denmark, Finland, Slovakia, Slovenia, Spain, Switzerland and Great Britain. In addition, that same year, the CNTB started advertising on the Russian search engine Yandex. The strategy for Google search engine advertising (impressions) was changed in 2015, when the focus was shifted from advertising destinations (e.g. Croatia, Split, Dubrovnik, Rovinj, etc.) to advertising key tourism-related terms (e.g. holidays, summer holidays, activity holidays, etc.). 
ToSEE - Tourism in Southern and Eastern Europe, Vol. 5, pp. 715-728, 2019

D. Turkalj, A. Biloš, R. Deželjin: THE EFFECTS OF DIGITAL PROMOTION INVESTMENT IN ...

Table 1: CNTB display and search advertising

\begin{tabular}{|c|c|c|c|}
\hline & $\mathbf{2 0 1 3}$ & $\mathbf{2 0 1 4}$ & $\begin{array}{c}\text { Index } \\
\mathbf{2 0 1 3 / 2 0 1 4}\end{array}$ \\
\hline Offline advertising & $30,072,277.41$ & $41,837,086$ & $39.12 \%$ \\
\hline Online advertising & $19,749,670.74$ & $32,308,446$ & $126.36 \%$ \\
\hline Online vs. offline advertising & $-34.33 \%$ & $-22.78 \%$ & $\mathrm{n} / \mathrm{a}$ \\
\hline Display advertising & $11,949,237.48$ & $20,787,298$ & $73.96 \%$ \\
\hline Ad impressions & $947,384,810$ & $749,507,391$ & $-20.89 \%$ \\
\hline Clicks & $\mathrm{n} / \mathrm{a}$ & $\mathrm{n} / \mathrm{a}$ & $\mathrm{n} / \mathrm{a}$ \\
\hline CTR & $\mathrm{n} / \mathrm{a}$ & $\mathrm{n} / \mathrm{a}$ & $\mathrm{n} / \mathrm{a}$ \\
\hline CPC & $\mathrm{n} / \mathrm{a}$ & $\mathrm{n} / \mathrm{a}$ & $\mathrm{n} / \mathrm{a}$ \\
\hline Search advertising & $4,643,889.73$ & $6,703,666$ & $44.35 \%$ \\
\hline Impressions & $50,487,882$ & $37,248,088$ & $-26.22 \%$ \\
\hline Clicks & $1,125,854$ & $1,184,935$ & $5.25 \%$ \\
\hline CTR & $2.23 \%$ & $3,18 \%$ & $\mathrm{n} / \mathrm{a}$ \\
\hline CPC & 4.12 & 5.66 & $137.40 \%$ \\
\hline Other online activities & $3,156,544$ & $4,817,482$ & $52.62 \%$ \\
\hline
\end{tabular}

\begin{tabular}{|c|c|c|c|c|}
\hline & $\mathbf{2 0 1 5}$ & $\begin{array}{c}\text { Index } \\
\mathbf{2 0 1 5 / 2 0 1 6}\end{array}$ & $\mathbf{2 0 1 6}$ & $\begin{array}{c}\text { Index } \\
\mathbf{2 0 1 5} / \mathbf{2 0 1 6}\end{array}$ \\
\hline Offline advertising & $21,781,583$ & $-47.94 \%$ & $27,862,036$ & $27.92 \%$ \\
\hline Online advertising & $41,671,793$ & $28.98 \%$ & $28,121,867 *$ & $-32.52 \%$ \\
\hline Online vs. offline advertising & $91.32 \%$ & $\mathrm{n} / \mathrm{a}$ & $0.93 \%$ & $\mathrm{n} / \mathrm{a}$ \\
\hline Display advertising & $32,457,896$ & $56.14 \%$ & $22,503,494.41$ & $-30.67 \%$ \\
\hline Ad impressions & $928,567,148$ & $23.89 \%$ & $805,085,031$ & $-13.30 \%$ \\
\hline Clicks & $\mathrm{n} / \mathrm{a}$ & $\mathrm{n} / \mathrm{a}$ & $1,888,989$ & $\mathrm{n} / \mathrm{a}$ \\
\hline CTR & $\mathrm{n} / \mathrm{a}$ & $\mathrm{n} / \mathrm{a}$ & $0.23 \%$ & $\mathrm{n} / \mathrm{a}$ \\
\hline CPC & $\mathrm{n} / \mathrm{a}$ & $\mathrm{n} / \mathrm{a}$ & 11.91 & $\mathrm{n} / \mathrm{a}$ \\
\hline Search advertising & $5,976,663$ & $-10.84 \%$ & $5,618,372.19$ & $-5.99 \%$ \\
\hline Impressions & $30,835,415$ & $-17.22 \%$ & $26,403,284$ & $-14.37 \%$ \\
\hline Clicks & 468,866 & $-60.43 \%$ & 305,032 & $-34.94 \%$ \\
\hline CTR & $1.52 \%$ & $\mathrm{n} / \mathrm{a}$ & $1.16 \%$ & $\mathrm{n} / \mathrm{a}$ \\
\hline CPC & 12.75 & $225.27 \%$ & 18.42 & $144.47 \%$ \\
\hline Other online activities & $3,237,234$ & $-32.80 \%$ & $\mathrm{n} / \mathrm{a}$ & $\mathrm{n} / \mathrm{a}$ \\
\hline
\end{tabular}

* There was a change in the way some items were recorded in the 2016 balance sheet, i.e. online and offline advertising were recorded as one item. The presented calculations are authors' own.

Source: HTZ (2013, 2015, 2016, 2017); Authors' calculations

In terms of the funds allocated for advertising (Table 1), there visible transition from traditional to digital advertising methods. Online advertising budget started increasing in 2013 , when it was $34 \%$ lower than that for offline advertising. In 2015 , it was almost double as high as the offline budget as a result of a large international brand image campaign. Finally, in 2016, the two budgets became almost equal. A large share of the online advertising budget was spent on display ads, online tourism and other specialised portals, and on portals that are part of the Google contextual network. The ratio of advertising budget spent on search engine marketing compared to display advertising was almost 1:2 in 2013. In 2016, it fell to 1:4, suggesting that display ads were more effective than search engine ads. An analysis was conducted of the 2016 data, as there 
ToSEE - Tourism in Southern and Eastern Europe, Vol. 5, pp. 715-728, 2019

D. Turkalj, A. Biloš, R. Deželjin: THE EFFECTS OF DIGITAL PROMOTION INVESTMENT IN ...

were no data on clicks for previous years, which shows that search and display advertising combined have a click through rate (CTR) of $0.26 \%$, while the average cost per click (CPC) was 13 HRK.

In order to measure the effectiveness of online advertising campaigns, it is necessary to analyze key performance indicators (KPI), such as click through rate (CTR) and cost per click (CPC). This can be done by comparing them with the industry averages that Google publishes each year. According to the Google AdWords Performance Benchmarks by Industry for 2016 (NoahDigital, 2016), which included 16 industries, among others, Travel and Hospitality, the average click through rate on the Google display network was $0.47 \%$ and $2.18 \%$ on the Google Search Network. The average click through rate for the CNTB on Google Display Network and Google Search Network was $0.23 \%$ and $1.16 \%$, respectively. The average CPC across all industries was USD 0.24 on the Display Network and USD 1.55 on the Search Network. In comparison to the CNTB CPCs, this represents an increase in CPC by about $773 \%$ for display and $185 \%$ for search engine advertising.

The large differences in the costs of online advertising, which is normally a cost effective medium, can be attributed to several factors. First, the difference in costs was not so large for search engine advertising in 2013 and 2014. Actually, it was within the industry average. However, the tourism market has become much more competitive lately, and Google's rules on competing for placement in search results have become stricter. By continuously monitoring the results of previous campaigns, minor adjustments can be made that will ultimately improve return on investment (ROI). A good starting point would be improving the Google AdWords Quality Score. This can be achieved by selecting keywords relevant to target audience, as well as by selecting alternative keywords that are less common in searches, but clearly indicate intent. Moreover, the quality of landing pages, user experience, the use of geotagging, and the use of so-called negative keywords, i.e. words that you do not want your ad to be linked with during search, prevent unwanted ad impressions (Thakur, 2017.).

\subsection{Communication and advertising on social networks}

Communication on social networks is extremely important for the CNTB because it enables it to present its main strategic marketing goals to the users in an effective way. Social network users are highly active consumers of advertising content - an ad is easily seen and recognized. Moreover, in addition to ad viewing, users often give feedback by liking, sharing, commenting, or clicking on the web link. Social networks are suitable for activities that cannot be planned in advance because they enable fast response to changes in the market and are quite effective marketing tools.

The CNTB has been active on social networks since May 2009. It targets all age groups (18-65+). Today, it is present on all major social networks - Facebook, Twitter, Foursquare, Instagram, YouTube, Google+, Pinterest, Picasa, Flickr, and LinkedIn. The main objectives and priorities of the CNTB's presence on social networks is to actively and continuously manage communication with social media users, increase their number and the quality of cooperation with them, and manage Croatia's image. In particular, the CNTB focuses on communicating key messages about products offered during the off- 
ToSEE - Tourism in Southern and Eastern Europe, Vol. 5, pp. 715-728, 2019

D. Turkalj, A. Biloš, R. Deželjin: THE EFFECTS OF DIGITAL PROMOTION INVESTMENT IN

season, as well as inland destinations, on Facebook and Twitter. Different activities are designed, profiles are optimized and upgraded, and global trends followed in the promotion of tourism destinations. Constant presence and communication in the language of the target audience is of great importance for raising brand awareness, improves connectivity, creates the basis for relationships with potential guests, increases their loyalty, allowing potential issues to be identified early on and resolved in a timely manner, while in turn the guest promotes the product or service on social media. This is why in 2015, in cooperation with the CNTB representative offices, official channels in the languages of source markets were maintained to improve the two-way communication between the CNTB and potential guests. In cooperation with local tourist offices in Croatia, new locally distinctive products were offered, which were not advertised on other CNTB channels (stories, legends, attractions, activities, cultural attractions, entertainment, night life, etc.).

The CNTB has focused mainly on Facebook because of its dominance on the market. At the end of 2016, the CNTB's Facebook page had 1,563,163 fans. For the most part, they come from the main source markets, i.e. Italy, Germany, Austria, Poland, the Czech Republic, Hungary, Slovakia, the UK, Slovenia, France and the Netherlands. Future plans include maintaining quality communication and attracting new users to its page on this social network. The CNTB's Facebook page is divided into the following pages: Global Pages (in English, Slovenian, Hungarian, Czech, and Slovak) and individual regional pages for individual countries, i.e. individual markets and languages: Austria, the US, Japan, Germany, Great Britain, Poland, Switzerland, Norway, Spain, the Netherlands, France, Italy, Sweden and Belgium. The page rating is 4.5 out of 5 (as voted by more than 16 thousand Facebook fans).

The CNTB's Twitter profile has over 73,000 users. The profile is used to provide information about Croatia's tourist offer and respond to inquiries and comments from potential tourists. It is important to note that the Croatian National Tourist Board won the City Nation Place "Best Use of Social Media" category for its Superbowl 2015 campaign.

The CNTB's Instagram profile (Croatia Full Of Life - @ croatiafulloflife) is updated with users' photos (i.e. user experiences and stories) but also with CNTB's own content. A hashtag was created (\#CroatiaFullOfLife) for users who give their permission for sharing photos taken during their trip in Croatia. To encourage users to participate, several user photographs are published daily, and once a week the most beautiful photo is chosen and posted on the CNTB's profile. By the end of 2016, the CNTB had about 120,000 followers and 335,625 photographs posted with the \#CroatiaFullOfLife. Following current trends, Instagram Live feature is used that allows users to stream videos in real time (e.g. a very successful live broadcast from Osijek, Kopački rit, Advent in Zagreb, Advent in Osijek). On average, 8.5 posts are made daily. In 2016, the Board received 8,534,834 likes and 84,273 comments. 
ToSEE - Tourism in Southern and Eastern Europe, Vol. 5, pp. 715-728, 2019

D. Turkalj, A. Biloš, R. Deželjin: THE EFFECTS OF DIGITAL PROMOTION INVESTMENT IN ...

The Croatian National Tourist Board also has an active channel for sharing video content on YouTube. All promotional video materials created by the CNTB and other tourist board offices are published on it. In 2016., the CNTB channel had 5,825 subscribers and a total of 13,302,961 views. During 2016, the promotional material on the CNTB's YouTube channel was viewed 1,920,533 times and had 593 likes and 19 comments.

Table 2: CNTB's social media advertising

\begin{tabular}{|c|c|c|c|}
\hline & $\mathbf{2 0 1 4}$ & $\begin{array}{c}\text { Index } \\
\mathbf{2 0 1 3 / 1 4}\end{array}$ & $\mathbf{2 0 1 5}$ \\
\hline Advertising on social networks & $4,817,482.00$ & $115.78 \%$ & $4,857,746.00$ \\
\hline Facebook - Number of fans & $1,396,000$ & $31.70 \%$ & $1,475,075$ \\
\hline HRK spent & $2,462,497.18$ & $232.01 \%$ & $1,477,066.18$ \\
\hline Impressions & $78,956,460$ & $77.17 \%$ & $50,835,433$ \\
\hline Interactions & $2,939,143$ & $-43.31 \%$ & $50,835,433$ \\
\hline Number of YouTube subscribers & 2,683 & n/a & 3,115 \\
\hline HRK spent & $2,311,602.65$ & $208.05 \%$ & $2,763,459.86$ \\
\hline Impressions & $26,166,945$ & $0.64 \%$ & $40,263,904$ \\
\hline Video content views & $2,547,627$ & $319.06 \%$ & $3,376,222$ \\
\hline Instagram - number of fans & 14,300 & n/a & n/a \\
\hline HRK spent & n/a & n/a & n/a \\
\hline Impressions & n/a & n/a & n/a \\
\hline Interactions & 61,870 & n/a & n/a \\
\hline Twitter-number of users & 19,000 & n/a & n/a \\
\hline HRK spent & $43,382,17$ & n/a & $671,544.38$ \\
\hline Impressions & n/a & n/a & $8,013,977$ \\
\hline Interactions & n/a & n/a & 389,709 \\
\hline
\end{tabular}

\begin{tabular}{|c|c|c|c|}
\hline & $\begin{array}{c}\text { Index } \\
\mathbf{2 0 1 4 / 2 0 1 5}\end{array}$ & $\mathbf{2 0 1 6}$ & $\begin{array}{c}\text { Index } \\
\mathbf{2 0 1 5} / \mathbf{2 0 1 6}\end{array}$ \\
\hline Advertising on social networks & $0.84 \%$ & $5,964,582$ & $22.78 \%$ \\
\hline Facebook - Number of fans & $5.66 \%$ & $1,562,075$ & $5.90 \%$ \\
\hline HRK spent & $-40.02 \%$ & $2,029,878.00$ & $37.43 \%$ \\
\hline Impressions & $-35.62 \%$ & $174,684,498$ & $243.63 \%$ \\
\hline Interactions & $1629.60 \%$ & $9,491,562$ & $-81.33 \%$ \\
\hline Number of YouTube subscribers & $16.10 \%$ & 5,798 & $86.13 \%$ \\
\hline HRK spent & $19.55 \%$ & $1,661,616.00$ & $-39.87 \%$ \\
\hline Impressions & $53.87 \%$ & $10,910,734$ & $-72.90 \%$ \\
\hline Video content views & $32.52 \%$ & $1,920,533$ & $-43.12 \%$ \\
\hline Instagram - number of fans & n/a & 130,000 & n/a \\
\hline HRK spent & n/a & $1,133,070.00$ & n/a \\
\hline Impressions & n/a & $15,961,797$ & n/a \\
\hline Interactions & n/a & 873,766 & n/a \\
\hline Twitter-number of users & n/a & 72,036 & n/a \\
\hline HRK spent & n/a & $933,443.00$ & $39.00 \%$ \\
\hline Impressions & n/a & $25,611,445$ & $219.58 \%$ \\
\hline n/a & $2,274,857$ & $483.73 \%$ \\
\hline
\end{tabular}

Source: HTZ (2013, 2015, 2016, 2017) 
ToSEE - Tourism in Southern and Eastern Europe, Vol. 5, pp. 715-728, 2019

D. Turkalj, A. Biloš, R. Deželjin: THE EFFECTS OF DIGITAL PROMOTION INVESTMENT IN ...

In order to reach their targeted audiences, brands use different social media platforms to engage with them. Different social media metrics should be monitored so that we could evaluate their performance over a certain period of time and also measure the effectiveness of each ad campaign. One of the most important areas for social media metrics is the cost per interaction or engagement (CPI/CPE). These metrics show us how much money did we spend on each interaction/engagement. Engagement is considered to be an action such as like, click, share, watch, post or any other desired interaction between the audience and an ad or content. As presented in Table 2. calculated CPI for Facebook is 0,21 HRK, Instagram 1,3 HRK, Twitter 0,41 HRK and YouTube 0,87. It's important to underline that every social media platform has its own benchmark for these indicators and should be observed separately. Through this analysis, it can be concluded the Facebook performs the most effective when it comes to return on investment for each interaction and when considering the total number of a fan base.

\subsection{CNTB website}

The CNTB website www.croatia.hr is continuously updated with new textual and multimedia content and information. Tourism-related section of the portal is written in 16 languages (Croatian, English, German, Italian, Czech, Polish, Slovak, French, Dutch, Hungarian, Russian, Slovenian, Japanese, Spanish and Danish).

Table 3: CNTB website use statistics

\begin{tabular}{|c|c|c|c|c|c|}
\hline www.croatia.hr & $\mathbf{2 0 1 4}$ & $\mathbf{2 0 1 5}$ & Index 2015/14 & $\mathbf{2 0 1 6}$ & Index 2016/15 \\
\hline No. of visitors & $3,998,959$ & $3,815,573$ & $-4.59 \%$ & $4,762,454$ & $+24.82 \%$ \\
\hline No. of visits & $5,175,577$ & $4,892,847$ & $-5.46 \%$ & $6,043,721$ & $+23.52 \%$ \\
\hline
\end{tabular}

Source: HTZ $(2013,2015,2016,2017)$

The website follows the latest trends, promotes the current campaign and products as well as news that the CNTB communicates through other channels in line with the new inspirational and informative communication strategy that focuses on the main Croatian tourism products. Given the increasing mobile technology use, content display is adapted to mobile devices. As the number of visitors to the website grew, so did the number of those who accessed the website using smartphones (a 234\% increase in 2016 as compared to 2015) and tablets (a 47\% increase). On the other hand, the number of desktop user visits decreased by $13 \%$. Most visits came from domestic visitors, followed by those from Germany, Italy, France and Great Britain. The majority of visitors were aged $25-34(24 \%)$, followed by those aged 35-44 (23\%), those aged 45-54 (18\%), and those aged $18-24(11 \%)$. Interestingly, the ratio of sexes was 56.35 percent in favour of female visitors.

\subsection{Mobile marketing}

Mobile marketing is becoming more and more important. According to Google's research, $60 \%$ of inquiries about a destination come from mobile devices, and $31 \%$ of leisure travellers and $53 \%$ of business travellers book trips using smartphones. Mobile devices make it easy to get around destinations and as many as $85 \%$ of travellers in general decide on what they will do at a destination after they get there. (Google, 2016). 
ToSEE - Tourism in Southern and Eastern Europe, Vol. 5, pp. 715-728, 2019

D. Turkalj, A. Biloš, R. Deželjin: THE EFFECTS OF DIGITAL PROMOTION INVESTMENT IN ...

Given the increasing number of mobile device users, mobile advertising is becoming an increasingly important advertising channel. By targeting mobile device users, considering their demographic and behavioural characteristics, Croatia is adequately presented as a desirable destination. The CNTB started to use mobile advertising in October 2015 by giving its mobile website www.croatia.hr a responsive design, which has become vital for promotional activities on mobile platforms. The Board invested a total of HRK 535,862 in mobile platforms by the end of that year. In 2016, the Board started advertising on mobile platforms in key markets. With a budged of HRK 2,000,000, 38,702,079 impressions and 472,234 interactions were recorded on the following markets: Germany, Great Britain, Austria, Italy, France, Poland, Sweden, Norway, Switzerland, Spain, Slovenia, the Czech Republic and Slovakia.

The CNTB launched its mobile application Croatia.hr for smartphones in 2011. The app was downloaded more than 10,000 times on Android devices. It was upgraded in 2013 to display in 16 languages. It enables users to see offers, activities and destinations, plan their trip, collect information, and share photos of interesting attractions and news about events on social media.

\subsection{Trips for travel bloggers}

During 2013, for the first time, trips were organised for 28 bloggers from seven international target markets that have a strong online influence on the global level. In 2014, 27 bloggers from nine countries visited Croatia. In 2015, there were 46 sponsored blogger visits from 12 countries, and in 2016, the CNTB invited 65 bloggers from 11 countries. The aim of this activity is to present Croatia to the international audience. Travel blogs improve online exchange of travel experiences and information on Croatia's tourist offer. Due to limited funds available for measuring the influence of blogs, the PR value of all blogs is difficult to quantify. However, there is no doubt that they contribute significantly to Croatia's online presence, reputation and promotion.

Table 4: Ratio of CNTB budget expenditures and tourist traffic in Croatia

\begin{tabular}{|c|c|c|c|}
\hline & $\mathbf{2 0 1 3}$ & $\mathbf{2 0 1 4}$ & Index \\
\hline Arrivals & $\mathbf{1 2 , 4 3 3 , 7 2 7}$ & $\mathbf{1 3 , 1 2 8 , 4 1 6}$ & $\mathbf{5 . 5 9 \%}$ \\
\hline Overnight stays & $\mathbf{6 4 , 8 1 8 , 1 1 5}$ & $\mathbf{6 6 , 4 8 3 , 9 4 8}$ & $\mathbf{2 . 5 7 \%}$ \\
\hline International arrivals & $10,948,366$ & $11,622,961$ & $6.16 \%$ \\
\hline Domestic arrivals & $1,485,361$ & $1,505,455$ & $1.35 \%$ \\
\hline Non-resident tourist overnight stays & $59,679,630$ & $61,323,572$ & $2.75 \%$ \\
\hline Domestic tourist overnight stays & $5,138,485$ & $5,160,376$ & $0.43 \%$ \\
\hline CNTB's total expenditures in HRK & $\mathbf{2 0 0 , 8 6 8 , 3 1 6}$ & $\mathbf{3 5 1 , 4 1 1 , 2 1 6}$ & $\mathbf{7 4 . 9 5 \%}$ \\
\hline HRK per arrival & 15.5 & 25.8 & $66.45 \%$ \\
\hline HRK per overnight stay & 2.7 & 4.7 & $74.07 \%$ \\
\hline Offline advertising & $\mathbf{3 0 , 0 7 2 , 2 7 7}$ & $\mathbf{4 1 , 8 3 7 , 0 8 6}$ & $\mathbf{3 9 . 1 2 \%}$ \\
\hline Online advertising (HRK) & $\mathbf{1 9 , 7 4 9 , 6 7 0}$ & $\mathbf{3 2 , 3 0 8 , 4 4 6}$ & $63.59 \%$ \\
\hline Online investment per arrival & $\mathbf{1 . 4 5}$ & $\mathbf{2 . 3 8}$ & $64.14 \%$ \\
\hline Offline investment per arrival & $\mathbf{2 . 4 2}$ & $\mathbf{3 . 1 9}$ & $\mathbf{3 1 . 7 6 \%}$ \\
\hline Online investment per overnight stay & $\mathbf{0 . 2 6}$ & $\mathbf{0 . 4 3}$ & $65.38 \%$ \\
\hline Offline investment per overnight stay & $\mathbf{0 . 4 6}$ & $\mathbf{0 . 6 3}$ & $\mathbf{3 5 . 6 4 \%}$ \\
\hline
\end{tabular}


ToSEE - Tourism in Southern and Eastern Europe, Vol. 5, pp. 715-728, 2019

D. Turkalj, A. Biloš, R. Deželjin: THE EFFECTS OF DIGITAL PROMOTION INVESTMENT IN ...

\begin{tabular}{|c|c|c|c|c|}
\hline & $\mathbf{2 0 1 5}$ & Index & $\mathbf{2 0 1 6}$ & Index \\
\hline Arrivals & $\mathbf{1 4 , 3 4 3 , 3 2 3}$ & $\mathbf{9 . 2 5} \%$ & $\mathbf{1 5 , 5 9 4 , 1 5 7}$ & $\mathbf{8 . 7 2 \%}$ \\
\hline Overnight stays & $\mathbf{7 1 , 6 0 5 , 3 1 5}$ & $\mathbf{7 . 7 0 \%}$ & $\mathbf{7 8 , 0 4 9 , 8 5 2}$ & $\mathbf{9 . 0 0 \%}$ \\
\hline International arrivals & $12,683,179$ & $9.12 \%$ & $13,808,532$ & $8.87 \%$ \\
\hline Domestic arrivals & $1,660,144$ & $10.28 \%$ & $1,785,532$ & $7.55 \%$ \\
\hline Non-resident tourist overnight stays & $65,862,680$ & $7.40 \%$ & $72,193,352$ & $9.61 \%$ \\
\hline Domestic tourist overnight stays & $5,742,635$ & $11.28 \%$ & $5,856,500$ & $1.98 \%$ \\
\hline CNTB's total expenditures in HRK & $\mathbf{3 4 0 , 1 5 5 , 7 0}$ & $\mathbf{- 3 . 2 0 \%}$ & $\mathbf{2 6 4 , 8 8 0 , 9 5}$ & $\mathbf{- 2 2 . 1 3 \%}$ \\
\hline HRK per arrival & 22.9 & $-11.24 \%$ & 16.2 & $-29.26 \%$ \\
\hline HRK per overnight stay & 4.3 & $-8.51 \%$ & 2.9 & $-32.56 \%$ \\
\hline Offline advertising & $\mathbf{2 1 , 7 8 1 , 5 8 3}$ & $\mathbf{- 4 7 . 9 4 \%}$ & $\mathbf{2 7 , 8 6 2 , 0 3 6}$ & $\mathbf{2 7 . 9 2 \%}$ \\
\hline Online advertising (HRK) & $\mathbf{4 1 , 6 7 1 , 7 9 3}$ & $28.98 \%$ & $\mathbf{2 8 , 1 2 1 , 8 6 7}$ & $-32.52 \%$ \\
\hline Online investment per arrival & $\mathbf{2 . 9 5}$ & $23.95 \%$ & $\mathbf{2 . 2 1}$ & $-25.08 \%$ \\
\hline Offline investment per arrival & $\mathbf{0 . 5 5}$ & $\mathbf{- 8 2 . 7 4 \%}$ & $\mathbf{0 . 3 9}$ & $\mathbf{- 2 9 . 0 9 \%}$ \\
\hline Online investment per overnight stay & $\mathbf{0 . 5 5}$ & $27.91 \%$ & $\mathbf{0 . 3 9}$ & $-29.09 \%$ \\
\hline Offline investment per overnight stay & $\mathbf{0 . 5 5}$ & $\mathbf{- 1 2 . 6 0 \%}$ & $\mathbf{0 . 3 9}$ & $\mathbf{- 2 9 . 0 9 \%}$ \\
\hline
\end{tabular}

Source: HTZ (2013, 2015, 2016, 2017); Institut za turizam (2015)

The increasing importance of online advertising is reflected in the ratio of online to offline marketing investments per arrival, which shows an almost inversely proportional trendline. In 2014, online and offline advertising investment per arrival was HRK 2.38 and 3.19, respectively. By 2016, the former decreased slightly to HRK 2.21 per arrival, while the latter fell to HRK 0.39 per arrival.

The CNTB's online advertising investment per night in 2014 rose from HRK 0.43 per night to HRK 0.39 per night in 2016, thus reaching the level of offline advertising investments, which was a bit higher than HRK 0.63 per night in 2014. Mobile advertising investments also rose by almost 3 times in 2016 compared to 2015.

\section{CONCLUSION}

So-called micro-moments in tourism, can be described as moments that people interested in travel arrangements are experiencing as a form of a customer journey in the online environment. These moments consist of browsing, researching, making the decision and finalizing the purchase via the Internet. Keeping up with the mentioned trend greatly influences and also justifies increased investment in online campaigns aimed at promoting tourism products and services. The growing interest of foreign tourists in Croatia's tourism offerings could be attributed to the Croatian National Tourist Board (CNTB) increased promotional efforts, with special emphasis on digital ones. Considering current market conditions, trends, and the importance of advertising and online media in tourism, in general, online advertising has become the most important part of the CNTB's marketing activities. The aim of this paper is to provide an overview of investments made by the CNTB in online promotion of its products and services and effects that it has had on the total number of visits. The authors analysed the digital promotion investments of the CNTB as well as the choice of individual digital communication channels. By analysing these data, it is possible to predict and advise a further increase in the latest forms of digital promotion which would lead to better 
ToSEE - Tourism in Southern and Eastern Europe, Vol. 5, pp. 715-728, 2019

D. Turkalj, A. Biloš, R. Deželjin: THE EFFECTS OF DIGITAL PROMOTION INVESTMENT IN

customer understanding of Croatia's diverse tourism offerings. Authors also recognize the rising importance of mobile presence when it comes to the promotion of tourism products, services, and destinations. When writing this paper, authors were faced with some research limitations. One of them was not being able to influence the choice of measured parameters and the second was the access to more recent data because they were still not available at the time. Nevertheless, these limitations also represent the possibility for further research that would provide more detailed insight into the potential of online promotion in tourism today and in the future.

\section{REFERENCES}

Adams, L., Burkholder, E., Hamilton, K. (2015), Micro-Moments: Your Guide to Winning the Shift to Mobile, Think with Google, viewed 10 February 2019 https:/www.thinkwithgoogle.com/marketingresources/micro-moments/micromoments-guide-pdf-download/

Biloš, A., Turkalj, D., \& Kelić, I. (2016), "Micro-Moments of User Experience: An Approach To Understanding Online User Intentions And Behaviour", Challenges of big data technology, 67.

Buhalis, D., \& Wagner, R. (2013), "E-destinations: Global best practice in tourism technologies and applications", In Information and communication technologies in tourism 2013, Springer, Berlin, Heidelberg, pp. 119-130. https://doi.org/10.1007/978-3-642-36309-2_11

Christou, E. (2011), "Exploring online sales promotions in the hospitality industry", Journal of Hospitality Marketing \& Management, 20(7), pp. 814-829.

Fatanti, M.N., \& Suyadnya, I.W. (2015), "Beyond User Gaze: How Instagram Creates Tourism Destination Brand?" Procedia-Social and Behavioral Sciences, 211, pp. 1089-1095.

Google (2016), How Micro-Moments Are Reshaping the Travel Customer Journey. viewed 11 February 2019 https://think.storage.googleapis.com/docs/micro-moments-reshaping-travel-customer-journeyb.pdf

Hays, S., Page, S.J., \& Buhalis, D. (2012), "Social media as a destination marketing tool: its use by national tourism organisations", Current issues in Tourism, 16(3), pp. 211-239. https://doi.org/10.1080/13683500.2012.662215

Hernández-Méndez, J., \& Muñoz-Leiva, F. (2015), "What type of online advertising is most effective for eTourism 2.0? An eye tracking study based on the characteristics of tourists", Computers in Human Behavior, 50, pp. 618-625.

HTZ (2013), Program tržišnih istraživanja viewed 11 February 2019 https://www.htz.hr/sites/default/files/2016-11/Program-trzisnih-istrazivanja-2013-.pdf

HTZ (2015), Godišnje financijsko izvješće za 2014. viewed 11 February 2019 https://www.htz.hr/sites/default/files/2016-11/Godisnje-financijsko-izvjesce-za-2014-godinu.pdf

HTZ (2016), Godišnje financijsko izvješće za 2015. viewed 11 February 2019 https://www.htz.hr/sites/default/files/2017-06/Godisnje-financijsko-izvjesce-za-2015.pdf

HTZ (2017), Godišnje financijsko izvješće za 2016. viewed 11 February 2019 https://www.htz.hr/sites/default/files/201804/Godišnje\%20financijsko\%20izvješće\%20za\%202016.pdf

Husson, T \& Ask, J. A. (2014), "Predictions 2015: Most Brands Will Underinvest In Mobile Brands Embracing The Mobile Mind Shift Will Pull Ahead Of Those Treating Mobile As Just Another Channel", Forrester Research, viewed 10 February 2019 https://www.forrester.com/report/Predictions+2015+Most+Brands+Will+Underinvest+In+Mobile /-/E-RES118065,

Institut za turizam (2015), Stavovi i potrošnja turista u Hrvatskoj - 2014 TOMAS Ljeto prezentacija viewed 10 February 2019 http://www.iztzg.hr/UserFiles/Pdf/Tomas/Tomas-ljeto-2014-Prezentacija.pdf

Inversini, A., Brülhart, C., \& Cantoni, L. (2011), "MySwitzerland. com: analysis of online communication and promotion", Information Technology \& Tourism, 13(1), pp. 39-49.

Ipsos (2015), HTZ Brand Tracker - Istraživanje snage Brenda. Internal document of CNTB

Kronenberg, K., Fuchs, M., Salman, K., Lexhagen, M., \& Höpken, W. (2016), "Economic effects of advertising expenditures-a Swedish destination study of international tourists", Scandinavian Journal of Hospitality and Tourism, 16(4), pp. 352-374. https://doi.org/10.1080/15022250.2015.1101013

Lai, W. H., \& Vinh, N. Q. (2013), "Online promotion and its influence on destination awareness and loyalty in the tourism industry", Advances in Management and Applied Economics, 3(3), pp. 15-30. 
ToSEE - Tourism in Southern and Eastern Europe, Vol. 5, pp. 715-728, 2019

D. Turkalj, A. Biloš, R. Deželjin: THE EFFECTS OF DIGITAL PROMOTION INVESTMENT IN ...

Lamsfus, C., Xiang, Z., Alzua-Sorzabal, A., \& Martín, D. (2013), “Conceptualizing context in an intelligent mobile environment in travel and tourism", In Information and communication technologies in tourism 2013, Springer, Berlin, Heidelberg. pp. 1-11.

Lawson, M. (2018), The AdWords Evolution: How we're bringing our advertising brand into the future, Think wih Google, viewed 13 February 2019

https://www.thinkwithgoogle.com/advertising-channels/search/google-ads/

Morosan, C. (2015), "The influence of DMO advertising on specific destination visitation behaviors", Journal of Hospitality Marketing \& Management, 24(1), pp. 47-75. https://doi.org/10.1080/19368623.2014.891962

Míguez-González, M.I., \& Fernández-Cavia, J. (2015), “Tourism and online communication: interactivity and social web in official destination websites", Comunicación y Sociedad, 28(4), pp. 17-31.

NoahDigital (2016), Google Adwords Benchmarks By Industry 2016, viewed 10 February 2019

https://www.noahdigital.ca/blog/google-adwords-benchmarks-by-industry-2016/

Ramaswamy, S. (2015), How Micro-Moments Are Changing the Rules, Think with Google, viewed 10 February 2019. https://www.thinkwithgoogle.com/articles/how-micromoments-are-changing-rules.html

Sambhanthan, A., \& Good, A. (2016), "Strategic advantage in web tourism promotion: an e-commerce strategy for developing countries", In International Business: Concepts, Methodologies, Tools, and Applications, IGI Global pp. 597-618.

$\mathrm{Sa}$, J. (2011), "Online advertising in the tourism industry and its impact on consumers-a study to investigate online advertising tools, the degree of usage and customer preferences", Tourism \& Management Studies, 7, pp. 101-107.

Standing, C., Tang-Taye, J.P., \& Boyer, M. (2014), "The impact of the Internet in travel and tourism: A research review 2001-2010", Journal of Travel \& Tourism Marketing, 31(1), pp. 82-113.

Stienmetz, J.L., Maxcy, J.G., \& Fesenmaier, D.R. (2015), "Evaluating destination advertising”, Journal of Travel Research, 54(1), pp. 22-35. https://doi.org/10.1177/0047287513514295

Thakur, D. (2017), What all you need to do to reduce high Cost per Click in AdWords?; Medium.com, viewed 10 February 2019 https://medium.com/@dineshsem/what-all-you-need-to-do-to-reduce-high-costper-click-in-adwords-79f895c7563a

Yazdanifard, R., \& Yee, L.T. (2014), "Impact of social networking sites on hospitality and tourism industries", Global Journal of Human-Social Science: E Economics, 14(8), pp. 1-5.

Davorin Turkalj, $\mathrm{PhD}$, Associate Professor

J. J. Strossmayer University of Osijek

Faculty of Economics in Osijek

Department of Marketing

Trg Ljudevita Gaja 7, 31000 Osijek, Croatia

Phone: 0038531224488

E-mail: davorin.turkalj@efos.hr

Antun Biloš, $\mathrm{PhD}$, Associate Professor

J. J. Strossmayer University of Osijek

Faculty of Economics in Osijek

Department of Marketing

Trg Ljudevita Gaja 7, 31000 Osijek, Croatia

Phone: 0038531224488

E-mail: antun.bilos@efos.hr

Renata Deželjin, MSc, Sector Director

Croatian National Tourist Board

Iblerov trg 10/IV, 10000 Zagreb, Croatia

E-mail: renata.dezeljin@htz.hr 